\title{
Gamification in thoracic surgery education: A slam dunk?
}

\author{
David D. Yuh, MD, FACS, FACC
}

From the Section of Cardiac Surgery, Yale University School of Medicine, New Haven, Conn

Disclosures: Author has nothing to disclose with regard to commercial support.

Received for publication Aug 2, 2015; accepted for publication Aug 3, 2015; available ahead of print Aug 28, 2015 .

Address for reprints: David D. Yuh, MD, FACS, FACC, Section of Cardiac Surgery, Yale University School of Medicine, 333 Cedar St, PO Box 208039, New Haven, CT 06520 (E-mail: david.yuh@yale.edu).

J Thorac Cardiovasc Surg 2015;150:1038-9

$0022-5223 / \$ 36.00$

Copyright $₫ 2015$ by The American Association for Thoracic Surgery

http://dx.doi.org/10.1016/j.jtcvs.2015.08.004

Mokadam and colleagues ${ }^{1}$ are to be congratulated for designing, implementing, and reporting on a gamification strategy intended to stimulate the use of simulation training and the thoracic surgery curriculum (TSC) by resident physicians in the field of cardiothoracic surgery. This effort reflects an earnest response by thoracic surgery educators to modernize residency-training paradigms in response to declining passing rates on the American Board of Thoracic Surgery board examinations, ${ }^{2}$ increasing emphasis on resident physicians' well-being and patient outcomes, and a perception that interest in thoracic surgery-related careers among the most highly qualified and sought-after resident physicians may be waning. ${ }^{3}$ By using "competition to fuel performance," the authors hoped to harness an assumed intrinsic competitive nature of cardiothoracic surgical resident physicians toward improved preparation.

As the authors note, there is substantial precedent for the use of game elements in education to increase trainee motivation and engagement. ${ }^{4-9}$ Coincident with the rise of sophisticated interactive media and video games, gamification strategies have gained popularity in recent years and are frequently used for graduate and postgraduate medical education. A recent survey revealed that $80 \%$ of US family medicine and internal medicine residency program directors reported using games in their respective programs. ${ }^{10}$

However, as intuitively beneficial as gamification toward learning may seem, there is little objective evidence that these strategies are actually effective in promoting learning or even engagement. Most contemporary empirical studies, including the present study, are handicapped by methodologic shortcomings, including lack of comparison groups, short evaluation periods, singular assessments, and lack of validated measures. In a comprehensive review of 24 empirical studies of gamification across different contexts, Hamari and colleagues ${ }^{11}$ found that very few possessed control groups and that only 2 studies reported entirely positive effects. Moreover, although most of these studies identified increased engagement and enjoyment initially, decreased levels of engagement and interest over time suggested a "novelty effect.", 12

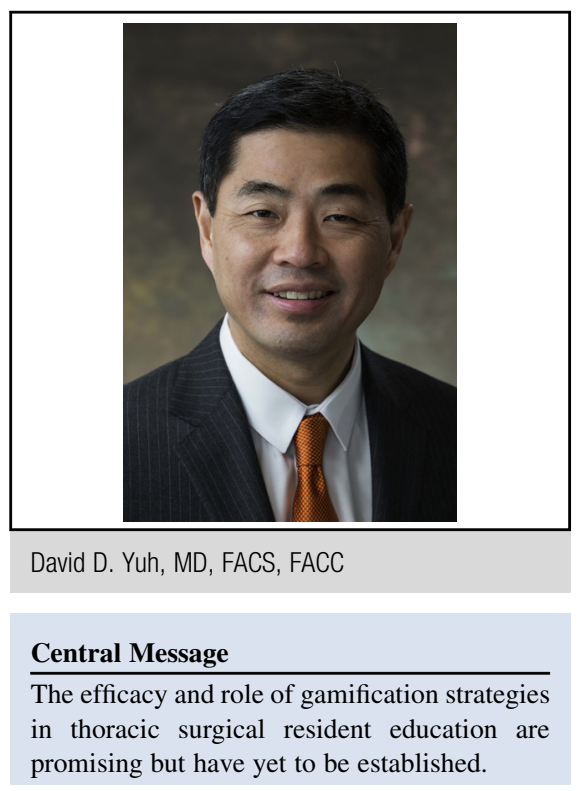

See Article page 1052 .

Many gamified systems, including the present one, use public settings (eg, leaderboards and video broadcasts) to facilitate social engagement and competition, but how these mechanics affect motivation, satisfaction, effort, learner empowerment, and downstream performance is heretofore unclear. In a controlled study, de-Marcos and colleagues ${ }^{13}$ found that whereas students participating in a reward/ leaderboard-based gamification system outperformed the control group on skill assignments, the control group students performed better on the final written examination designed to assess course knowledge.

Educators generally agree that intrinsically motivated trainees; that is, in whom the desire to learn comes from within, are more engaged, retain information better, and are generally happier than extrinsically motivated trainees (ie, driven by external forces such as peer pressure or winning a competition). ${ }^{14}$ In fact, a substantial body of education research cautions that, under certain conditions, extrinsic rewards and competition can actually backfire and decrease preexisting intrinsic motivation. ${ }^{15,16}$ The formidable challenge, of course, is nurturing self-motivation across a broad spectrum of resident aptitudes, interests, and career aspirations.

As the authors acknowledge, their study is handicapped in that one of the authors' primary objectives, stimulating actual TSC use, could not be tracked. Furthermore, its voluntary format self-selected for highly motivated, technically proficient residents. It remains to be seen whether this 
strategy would similarly promote more intensive study and technical simulation among a likely larger segment of resident physicians who are neither particularly interested nor flourish in public gaming settings. Another legitimate question is whether these high-profile public competitions, although perhaps entertaining spectator sport, emphasize the qualities we want from our resident physicians. Are we fostering an elite group of show-offs rather than motivating nonparticipants to engage in self-study and technical simulation? I was drawn to the field of cardiothoracic surgery by admiring the quiet confidence of my faculty mentors who, as a group, were widely acknowledged as the most outstanding, well-mannered surgeons in the institution, yet did not project a need for public display to reinforce this fact.

The value of this exercise lies in the successful design and implementation of a gamification strategy that empirically stimulated interest and enthusiasm for self-study and technical simulation, albeit among a self-selected group of highly motivated cardiothoracic surgical resident physicians. Future investigation incorporating control groups and/or downstream objective assessments of knowledge and technical skill to determine whether participation and high performance in such gamification constructs leads to a higher propensity for success on the American Board of Thoracic Surgery certification examinations and objective measures of technical proficiency would be interesting and help formulate new training strategies. It is also encouraging that the TSC platform is being modified so that more refined use information will be tracked and analyzed. Although it seems unlikely that sustaining a high level of enthusiasm through repeated, frequent game play alone would be practical or even successful over the course of an entire residency, this strategy could be used in concert with other personalized efforts to mentor and nurture interest and motivation within all of our resident physicians.

\section{References}

1. Mokadam NA, Lee R, Vaporciyan AA, Walker JD, Cerfolio RJ, Hermsen JL, et al. Gamification in thoracic surgical education: Using competition to fuel performance. J Thorac Cardiovasc Surg. 2015;150:1052-8.

2. Moffatt-Bruce S, Ross P, Williams T Jr. American Board of Thoracic Surgery examination: fewer graduates, more failures. J Thorac Cardiovasc Surg. 2014;147: 1464-9.

3. Crawford F Jr. Thoracic surgery education-past, present, and future. Ann Thorac Surg. 2005;79(6 Suppl):S2232-7.

4. Van Nuland S, Roach V, Wilson T, Belliveau D. Head to head: the role of academic competition in undergraduate anatomic education. Anat Sci Educ. October 15, 2014 [Epub ahead of print].

5. Snyder E, Hartig J. Gamification of board review: a residency curricular innovation. Med Educ. 2013;47:524-5.

6. Nevin C, Westfall A, Rodriguez J, Dempsey DM, Cherrington A, Roy B, et al. Gamification as a tool for enhancing graduate medical education. Postgrad Med J. 2014;90:685-93.

7. Lin D, Park J, Liebert C, Lau J. Validity evidence for surgical improvement of clinical knowledge ops: a novel gaming platform to assess surgical decision making. Am J Surg. 2015;209:79-85.

8. Kerfoot B, Kissane N. The use of gamification to boost residents' engagement in simulation training. JAMA Surg. 2014;149:1208-9.

9. Kerfoot B, Baker H. An online spaced-education game to teach and assess resi dents: a multi-institutional prospective trial. J Am Coll Surg. 2012;214:367-73.

10. Akl E, Gunukula S, Mustafa R, Wilson MC, Symons A, Moheet A, et al. Support for and aspects of use of educational games in family medicine and internal medicine residency programs in the US: a survey. BMC Med Educ. 2010;10:26-31.

11. Hamari J, Koivisto J, Sarsa H. Does gamification work? A literature review of empirical studies on gamification. Paper presented at 2014 47th Hawaii International Conference on System Sciences; January 6-9, 2014; Waikoloa, Hawaii.

12. Koivisto J, Hamari J. Demographic differences in perceived benefit from gamification. Comp Hum Behav. 2014;35:179-88.

13. de-Marcos L, Dominguez A, Saenz-de-Navarrete J, Pages C. An empirical study comparing gaification and social networking on e-learning. Computers Educ 2014; 75:82-91.

14. Deci E, Ryan R. The "what" and "why" of goal pursuits: human needs and the self-determination of behavior. Psychol Inquiry. 2000;11:227-68.

15. Tang S, Hall V. The overjustification effect: a meta-analysis. Appl Cog Psych. 1995;9:365-404.

16. Deci E, Koestner R, Ryan R. Extrinsic rewards and intrinsic motivation in education: reconsidered once again. Rev Educat Res. 2001;71:1-27. 